\title{
Characterization of Novel Oxidation Products of Cysteine in an Active Site Motif Peptide of PTP1B
}

\author{
Vivekananda Shetty and Thomas A. Neubert \\ Kimmel Center for Biology and Medicine at the Skirball Institute and Department of Pharmacology, New \\ York University School of Medicine, New York, New York, USA
}

We investigated the formation of hydroxyl radical $(\mathrm{OH})$ and $\mathrm{H}_{2} \mathrm{O}_{2}$ mediated oxidation products of a synthetic peptide, HCSAGIGRS, which is an active site sequence motif of protein tyrosine phosphatase 1B (PTP1B). We determined that a novel cysteine sulfinamide $\mathrm{HC}[\mathrm{S}(\mathrm{O}) \mathrm{N}] \mathrm{SAGIGRS}$ is produced in the oxidation reaction by Fenton reagents $\left(\mathrm{Fe}^{+2} / \mathrm{H}_{2} \mathrm{O}_{2}\right)$ as well as by $\mathrm{H}_{2} \mathrm{O}_{2}$. These products were characterized by tandem mass spectrometry experiments on both singly and doubly charged precursor ions. $\mathrm{MS}^{3}$ experiments using an ion trap instrument as well as LC-MS/MS experiments using a quadrupole time-of-flight (Q-TOF) instrument demonstrated that $\mathrm{HC}[\mathrm{S}(\mathrm{O}) \mathrm{N}] \mathrm{SAGIGRS}$ is not a water loss product of cysteine sulfinic acid [ $\mathrm{HC}\left(\mathrm{SO}_{2} \mathrm{H}\right)$ SAGIGRS]. We also obtained data from tandem mass spectrometry experiments that provided evidence for the existence of stable cysteine sulfenic acid [HC(SOH)SAGIGRS] in solution. A mechanism for the formation of the cysteine sulfinamide product is proposed based on the above experimental results. The preparation and identification of cysteine sulfinamide in this study may provide insight into the mechanism of both $\mathrm{OH}$ and $\mathrm{H}_{2} \mathrm{O}_{2}$ induced oxidation reactions of protein tyrosine phosphatases. (J Am Soc Mass Spectrom 2009, 20, 1540-1548) @ 2009 Published by Elsevier Inc. on behalf of American Society for Mass Spectrometry

$\mathrm{P}$ rotein tyrosine phosphatases (PTPs) comprise an important class of enzymes involved in control of the cell cycle and signal transduction by regulating levels of protein tyrosine phosphorylation in response to cellular signals [1-5]. Because of this key function, PTPs have been implicated in the development of cancer, diabetes, rheumatoid arthritis, and hypertension [6, 7]. Cysteine residues in PTPs are highly susceptible to oxidation by reactive oxygen species (ROS)/reactive nitrogen species (RNS), because at neutral $\mathrm{pH}$ they exist in thiolate anion $\left(\mathrm{Cys}^{-} \mathrm{S}^{-}\right)$form due to their low $\mathrm{pK}_{\mathrm{a}}(4.7-5.4)$ [8]. This property directly influences and inhibits PTP activity during signaling processes. Much biochemical evidence suggests that PTP's activity is regulated through reversible oxidation of the catalytic cysteine to cysteine sulfenic acid intermediate by low micromolar concentrations of $\mathrm{H}_{2} \mathrm{O}_{2}$ [9]. These active sites can be reactivated by thioredoxin electron donors [10] and reduction with glutathione [11]. PTP1B has been studied extensively as it is an important enzyme in the negative regulation of the insulin receptor [12,13], and a therapeutic target in type II diabetes and obesity [14]. In light of the critical biologic role of PTP1B and its regulation by cysteine

Address reprint requests to Dr. T. A. Neubert, Kimmel Center for Biology and Medicine at the Skirball Institute and Department of Pharmacology, New York University School of Medicine, Skirball Institute Lab 5-18 540, First Avenue, New York, NY 10016, USA. E-mail: neubert@saturn.med. nyu.edu oxidation, Salmeen et al. used X-ray crystallography and mass spectrometry to discover a novel "cysteine sulfenamide" species in the oxidation of PTP1B by $\mathrm{H}_{2} \mathrm{O}_{2}$. This species was identified as a reversible intermediate in the oxidative inhibition of PTP1B, which may allow reactivation of PTP1B by biological thiols [15].

Hydroxyl radicals $(\mathrm{OH})$ are extremely reactive and can cause irreversible damage to all cellular components [16-18]. They can be produced by the reduction of $\mathrm{H}_{2} \mathrm{O}_{2}$ in the presence of iron via the "Fenton reaction" [19]. Although this reaction is a major source for $\mathrm{OH}$ formation in cells, these radicals often can be produced from other cellular oxidants like $\mathrm{ONOOH}$ in their homolytic cleavage reactions [20-22]. Indeed, most of the amino acid residues of proteins are potential targets for oxidation by $\mathrm{OH}$ generated by high concentrations of $\mathrm{H}_{2} \mathrm{O}_{2}$ and $\mathrm{Fe}$ (II) or by ionizing radiation [23-31]. Increasing evidence suggests that $\mathrm{OH}$ are also involved in regulating signaling processes of wide variety of proteins including PTPs [32,33]. Corroborating the role of $\mathrm{OH}^{-}$in the control of PTPs, Caselli et al. [34] examined the inactivation mechanism of low molecular weight PTPs by $\mathrm{H}_{2} \mathrm{O}_{2}$ in vitro and found that addition of metal chelator to the reaction mixtures caused $17 \%$ and $28 \%$ decrease in the inactivation of IF1 and IF2, respectively. These investigators demonstrated that $\mathrm{OH}^{\prime}$ partially contributes to this inactivation. In light of this, we have studied the structures of $\mathrm{OH}^{\cdot}$ and $\mathrm{H}_{2} \mathrm{O}_{2}$ 
mediated oxidation products of PTP1B in vitro. To minimize the complexity of diverse oxidation products, we have selected a short synthetic peptide, HCSAGIGRS, which mimics the active site sequence motif of PTP1B. Here we report the preparation and characterization by tandem mass spectrometry of cyclic cysteine sulfinamide and cysteine sulfenic acid formed in solution by reactive oxygen species $\left(\mathrm{OH}\right.$ and $\mathrm{H}_{2} \mathrm{O}_{2}$ ) mediated oxidation reactions of HCSAGIGRS. These novel oxidative species of the catalytic cysteine of PTP1B have been proposed as intermediate steps towards irreversible inactivation of PTB1B [35], but to the best of our knowledge never before directly observed in solution.

\section{Experimental}

The synthetic peptide HCSAGIGRS was purchased from GenScript Corp., Scotch Plains, NJ, USA. This peptide was oxidized using Fenton reagents $\left(\mathrm{Fe}^{+2} /\right.$ $\mathrm{H}_{2} \mathrm{O}_{2}$ ) as reported previously [36]. Briefly, $1 \mathrm{mM}$ peptide solution was incubated at room temperature in the presence of $0.5 \mathrm{mM} \mathrm{FeSO}_{4}$ and $0.2 \mathrm{mM} \mathrm{H}_{2} \mathrm{O}_{2}$ for $\sim 30$ min. The reaction was terminated by adding aliquots of methionine solution until its concentration reached 1 $\mathrm{mM}$. Similar conditions were used for the oxidation of HCSAGIGRS by $\mathrm{H}_{2} \mathrm{O}_{2}$ except that the concentration of $\mathrm{H}_{2} \mathrm{O}_{2}$ was $100 \mu \mathrm{M}$. In direct infusion MS and MS/MS experiments on a Q TOF Micro instrument (Micromass, Manchester, United Kingdom), 50\% acetonitrile in 0.1\% formic acid was used as the carrier and electrospray solvent with a flow rate of $500 \mathrm{~nL} / \mathrm{min}$. A $1-\mu \mathrm{L}$ aliquot of $2-\mu \mathrm{M}$ sample solution was injected via a divert valve in each run under the following source conditions: spray voltage 1500 to $1800 \mathrm{~V}$, cone voltage $40 \mathrm{~V}$, and source temperature $80^{\circ} \mathrm{C}$. Argon was used as a collision gas for all MS/MS experiments. The low mass and high mass resolution of the quadrupole mass filter before the TOF analyzer were adjusted for transmission of precursor ions through a mass window of only 1.0 Da. Each spectrum was obtained by averaging $\sim 25$ scans, and the scan time was $1 \mathrm{~s} / \mathrm{scan}$. The Q-TOF Micro instrument was calibrated with [Glu1]-fibrinopeptide B, and the data in both MS and MS/MS modes were acquired at 5000 resolution. Additional direct infusion tandem mass spectrometry $\left(\mathrm{MS}^{2}\right.$ and $\mathrm{MS}^{3}$ ) experiments were carried out on an LCQ-Deca XP (Thermo Finnigan, San Jose, CA, USA) equipped with a nano-ESI source (Jamie Hill Instrument Services, Arlington, MA, USA). The carrier solution was $50 \%$ acetonitrile in $0.1 \%$ formic acid with a flow rate of $300-500 \mathrm{~nL} / \mathrm{min}$. The oxidation reaction mixture was diluted 5-fold in carrier solution, and infused directly into the mass spectrometer with spray voltage of $2.5 \mathrm{kV}$ and temperature for the heated capillary of $150{ }^{\circ} \mathrm{C}$. The mass width for precursor ion selection in MS/MS was $1 \mathrm{Da}$, and the normalized collision energy was optimized $(18 \%-25 \%)$ so that the precursor ions were clearly present but not the most abundant ions in the product-ion spectra. Each spec- trum was obtained by averaging $\sim 50$ scans, and the time for each scan was $0.1 \mathrm{~s}$.

Data-dependent nanoLC-MS/MS experiments were carried out using a Waters nanoAcquity UPLC and a Waters Q-TOF Premier mass spectrometer (Milford, MA, USA). The analytical column was a Waters Symmetry C18, $100 \mu \mathrm{m}$ i.d. $\times 15 \mathrm{~cm}$, with $3.5 \mu \mathrm{m}$ particles. Mobile phase A was $2 \%$ acetonitrile $/ 0.1 \%$ formic acid, while mobile phase B was $90 \%$ acetonitrile $/ 0.1 \%$ formic acid in water. The gradient was $5 \%-90 \%$ B over 45 min at a flow rate of $200 \mathrm{~nL} / \mathrm{min}$. Automatic switching between MS and MS/MS modes was controlled by MassLynx 4.0 (Micromass), dependent on both signal intensity and charge states from MS to MS/MS, and on either signal intensity or time from MS/MS to MS.

\section{Results and Discussion}

The peptide HCSAGIGIRS was incubated with Fenton reagent to form cysteine oxidation products as described in the Experimental section, and infused directly into the Q-TOF Micro instrument for mass spectrometry analysis. The partial mass spectrum of the above reaction mixture is shown in Figure 1a. This spectrum exhibits singly charged ions at $m / z$ 901.4, 903.4, 919.4 and 935.4, which corresponds to the +14 , 16, 32, and 48 Da modifications of HCSAGIGRS $(\mathrm{m} / \mathrm{z}$ 887.4), respectively. The latter three products at $m / z$ 903.4, 919.4, and 935.4 were characterized as cysteine sulfenic acid (Figure 1b), cysteine sulfinic acid (Figure 1c), and cysteine sulfonic acid (Figure 1d) products based on the characteristic fragment ions formed in their MS/MS spectra. We observed similar MS/MS spectra for the doubly charged ions of the oxidation products (data not shown).

\section{Characterization of Cysteine Sulfinamide (HC[S(O)N]SAGIGRS)}

The MS/MS spectra of singly $(m / z$ 901.3) and doubly $(\mathrm{m} / \mathrm{z}$ 451.2) charged ions of a product formed in the oxidation reaction of HCSAGIGRS by Fenton reagents are shown in Figure $2 b$ and Figure $3 b$, respectively. Compared with the MS/MS spectrum of unmodified peptide HCSAGIGRS in Figure 2a, a mass shift of $14 \mathrm{Da}$ can be seen in the MS/MS spectrum in Figure $2 b$ for several $\mathbf{b}$ ions $\left[\mathbf{b}_{4}(m / z 413.1), \mathbf{b}_{5}(m / z 470.1), \mathbf{b}_{6}(m / z\right.$ 583.2), $\mathrm{b}_{8}+\mathrm{H}_{2} \mathrm{O}(\mathrm{m} / z$ 814.3)] as well as for three a ions, $\left[\mathbf{a}_{4}(m / z 385), \mathbf{a}_{5}(m / z 442.2)\right.$, and $\left.\mathbf{a}_{6}(m / z 555.2)\right]$. The formation of a $\mathrm{y}_{6}(\mathrm{~m} / \mathrm{z} 560.3)$ ion rules out modification of the AGIGRS fragment. The characteristic ion at $\mathrm{m} / \mathrm{z}$ 853 due to direct loss of a neutral SO from $\mathrm{M}+\mathrm{H}^{+}$ions of $\mathrm{m} / \mathrm{z} 901$ and an ion at $\mathrm{m} / \mathrm{z} 207\left(\mathrm{~b}_{2}\right.$-SO) localize the site of modification to the cysteine residue. The MS/MS spectrum of the doubly charged ion $(\mathrm{m} / \mathrm{z} 451.2)$ in Figure $3 \mathrm{~b}$ displayed an additional characteristic $\mathrm{y}_{8}$ ion at $m / z 764$, along with $\mathrm{y}_{3}(m / z 319), \mathrm{y}_{5}(\mathrm{~m} / z 489.2), \mathrm{y}_{6}(\mathrm{~m} / \mathrm{z}$ $560.3)$, and $b_{2}-\mathrm{SO}(\mathrm{m} / \mathrm{z} 207.1)$ ions, revealing that cys- 


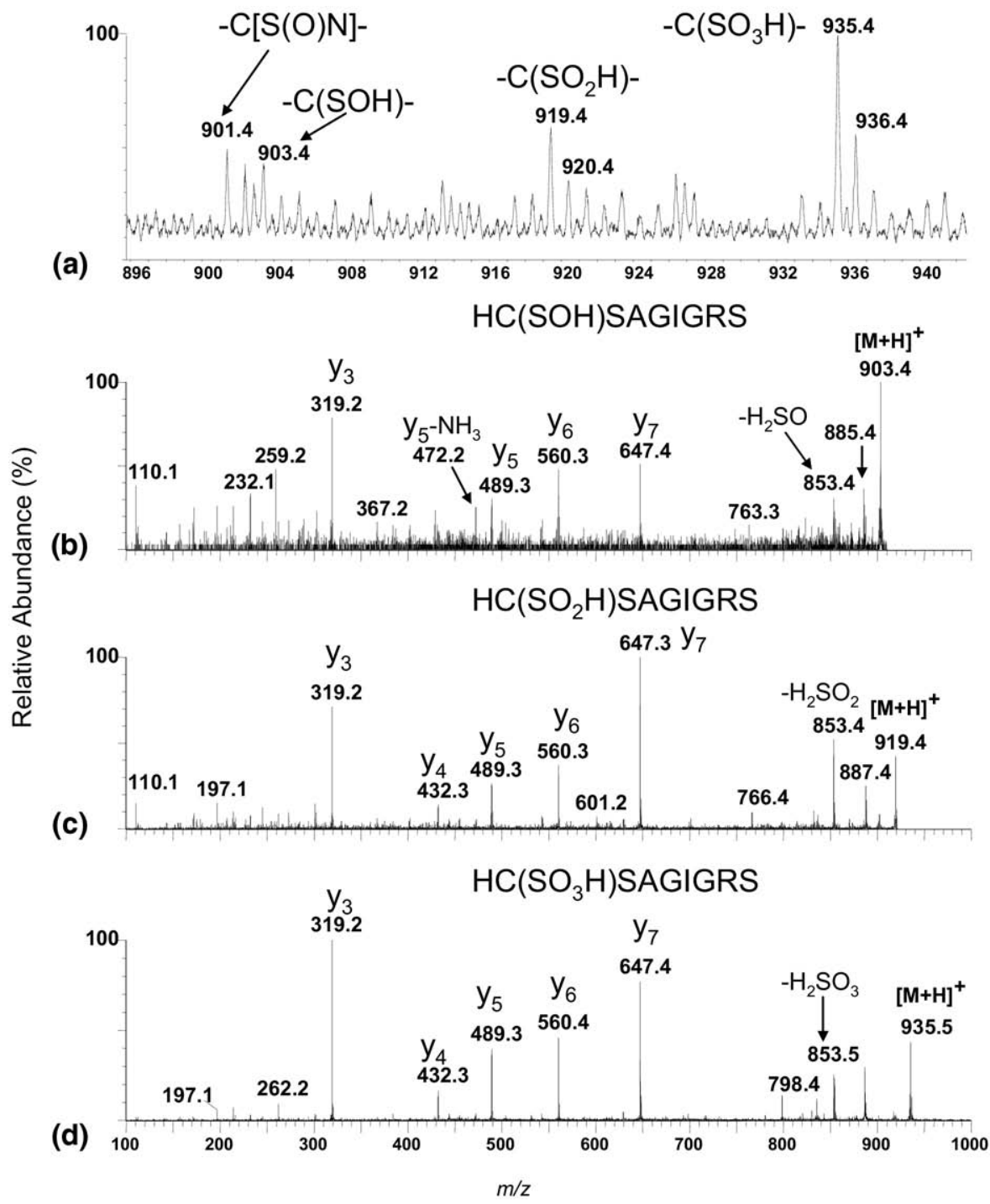

Figure 1. (a) Q-TOF partial mass spectrum of $(\mathrm{M}+\mathrm{H})^{+}$ions of products formed in the oxidation reaction of HCSAGIGRS peptide with Fenton reagent. Q-TOF MS/MS spectra of $(\mathrm{M}+\mathrm{H})^{+}$ions (b) HC(SOH)SAGIGRS (m/z 903.4); (c) HC( $\left.\mathrm{SO}_{2} \mathrm{H}\right)$ SAGIGRS $\left(\mathrm{m} / \mathrm{z}\right.$ 919.4); and (d)HC(SO$\left.{ }_{3} \mathrm{H}\right)$ SAGIGRS $(\mathrm{m} / \mathrm{z}$ 935.4).

teine is modified by $14 \mathrm{Da}$. Thus, the above results suggest that an intramolecular covalent bond is formed between the oxidized cysteine residue and the nitrogen of serine, giving rise to a cysteine sulfinamide product. The structure of this product and its key fragmentation pathways are depicted in Scheme 1. Although the formation of the $y_{7}$ ion $(m / z$ 647) in MS/MS spectra of both singly and doubly charged sulfinamide precursor ions (Figures $2 \mathrm{~b}$ and $3 \mathrm{~b}$ ) would require complex rearrangement reactions in the gas phase, such rearrangements under CID conditions were previously reported for peptides with sequences PFKCG [37] and PRCGVPDVA [38]. For example, a prominent gasphase rearrangement ion $\left(m / z 373, b_{3}\right)$ was observed in the MS/MS spectra of cyclic cysteine sulfonamide, cysteine sulfinamide, and cysteine sulfenamide products formed in the oxidation of PFKCG by HOCl [37].
With these precedents in mind, we believe the $\mathrm{y}_{7}$ ion $(m / z$ 647) in MS/MS spectra of both singly and doubly charged precursor ions (Figures $2 b$ and $3 b$ ) may be formed by a similarly complex gas-phase rearrangement reaction. We do not believe these spectra provide evidence for a cysteine sulfine because we do not observe the predicted ions of $m / z 839.4$ (Figure $2 b$ ) or $\mathrm{m} / \mathrm{z} 420.4$ (Figure $3 \mathrm{~b}$ ) caused by the neutral loss of a stable thio-ketene $\left(\mathrm{CH}_{2}=\mathrm{S}=\mathrm{O}\right)$ from a cysteine sulfine. Recently, Gates et al. demonstrated, by using a small organic molecule model of the PTP1B active site, that the sulfenic acid residue possesses sufficient electrophilicity to drive a cyclization reaction with a neighboring amide group, which leads to the formation of a 3-isothiazolidinone analog [39]. In this study, there was no evidence for the formation of cysteine sulfine from the sulfenic acid intermediate. We also do not believe 


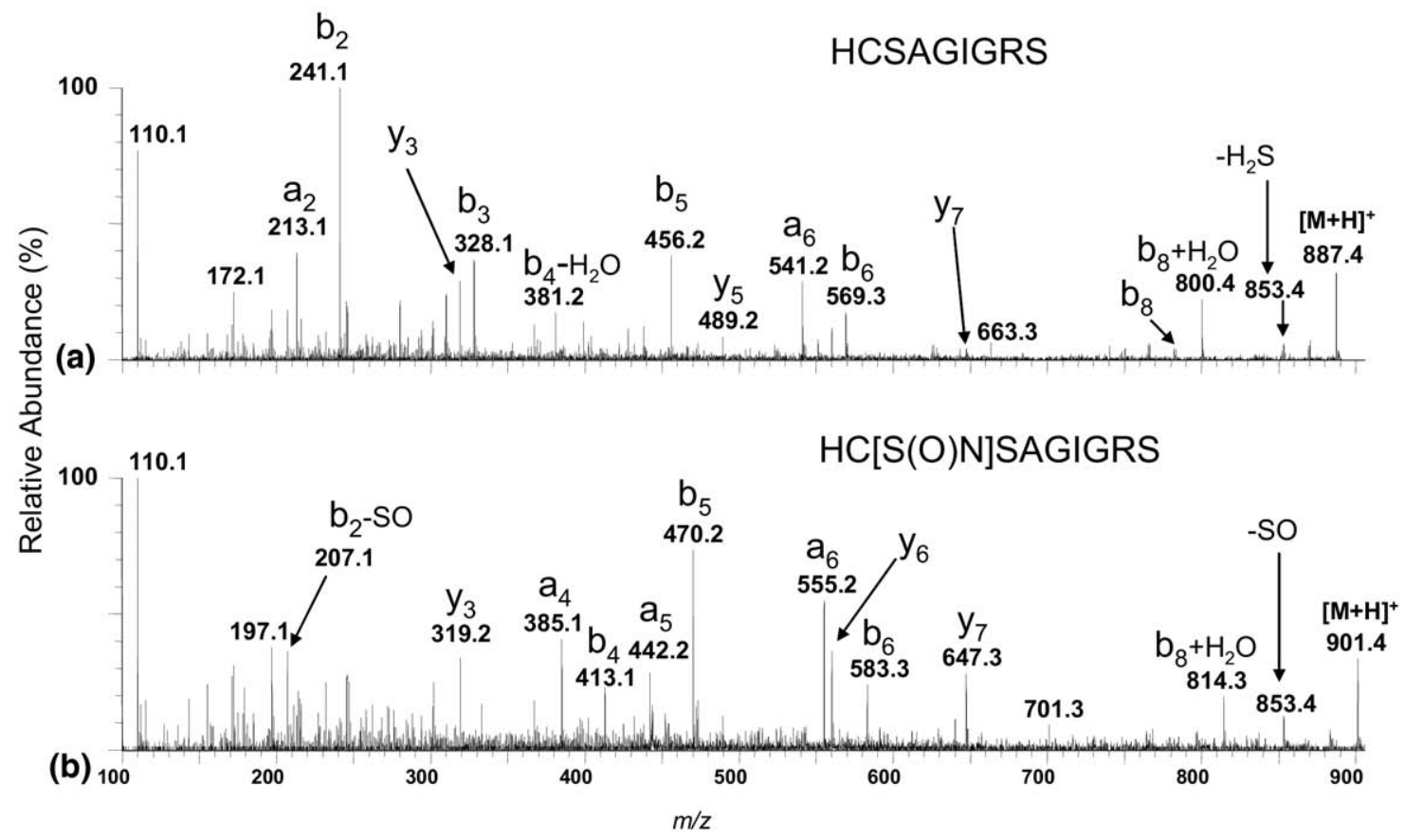

Figure 2. Q-TOF MS/MS spectra of $(\mathrm{M}+\mathrm{H})^{+}$ions of (a) HCSAGIGRS $(\mathrm{m} / \mathrm{z}$ 887.4) and (b) HC[S(O)N]SAGIGRS $(\mathrm{m} / \mathrm{z}$ 901.4).

our data can be explained by oxidation of histidine because the formation of an abundant histidine immonium ion (Figures $2 \mathrm{~b}$ and $3 \mathrm{~b}$ ) at $\mathrm{m} / \mathrm{z} 110$ and a shift of $\mathrm{y}_{8}$ ion from $\mathrm{m} / \mathrm{z} 750$ (Figure 3a) to $\mathrm{m} / \mathrm{z} 764$ (Figure 3b) strongly suggest that histidine is not modified. When we infused the unmodified peptide $(\mathrm{m} / \mathrm{z}$ 887.4) solution directly in to the MS, we found no oxidation product formed at $m / z$ 901, suggesting oxidation did not occur in the electrospray source of the mass spectrometer (data not shown).

Interestingly, the MS/MS spectrum shown in Figure $3 \mathrm{~b}$ is very similar to that of the doubly charged Q-TOF MS/MS spectrum of $\mathrm{HC}\left(\mathrm{SO}_{2} \mathrm{H}\right)$ SAGIGRS $(\mathrm{m} / \mathrm{z} 460.2$, +2 ) (Figure 4a) except for the $y_{8}$ fragment ion at $m / z 764$ and differences in the relative intensities of all other fragment ions. The formation of ions at $\mathrm{m} / \mathrm{z} 273$ and

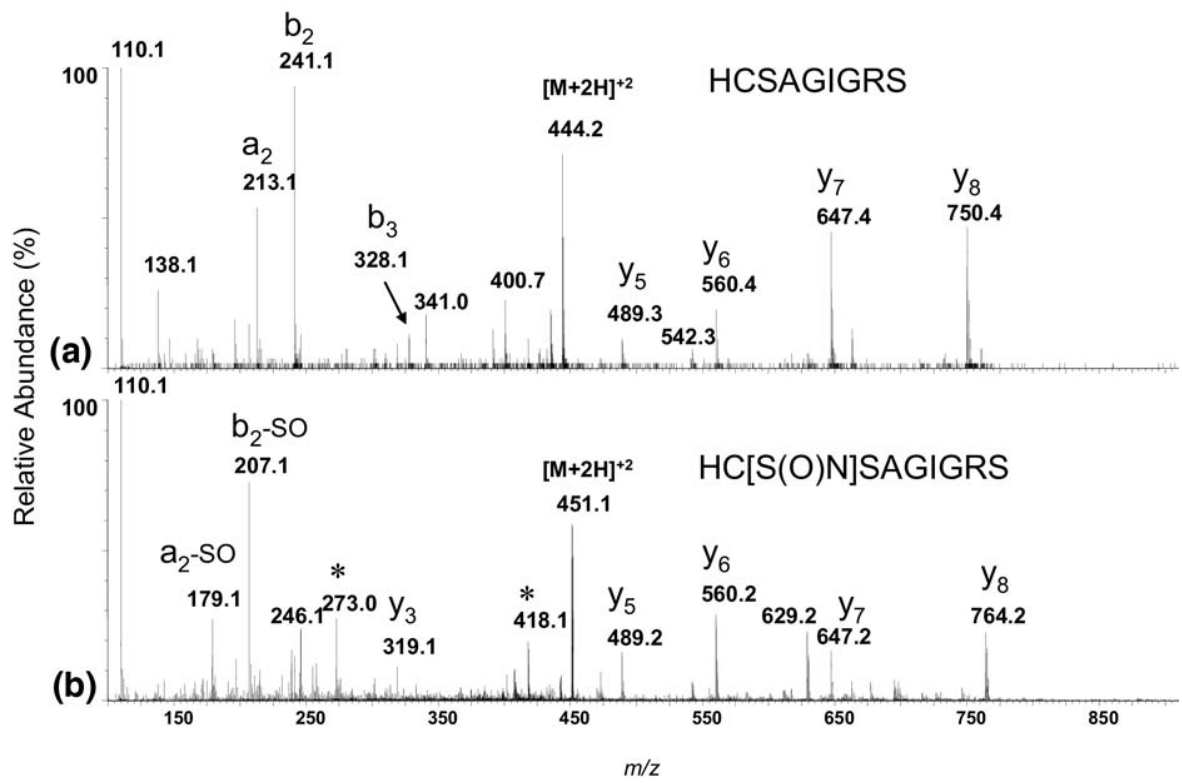

Figure 3. Q-TOF MS/MS spectra of $(\mathrm{M}+2 \mathrm{H})^{+2}$ ions of (a) HCSAGIGRS $(\mathrm{m} / \mathrm{z} 444.2)$ and (b) cyclic cysteine sulfinamide HC[S(O)N]SAGIGRS $(\mathrm{m} / \mathrm{z} 451.1)$. Ions at $\mathrm{m} / \mathrm{z} 273.0$ and 418.1, indicated with an asterisk, are most likely derived from the isobaric contaminant of $m / z 451.2(+2)$ ions formed by the in-source loss of water from $\mathrm{HC}\left(\mathrm{SO}_{2} \mathrm{H}\right)$ SAGIGRS. 


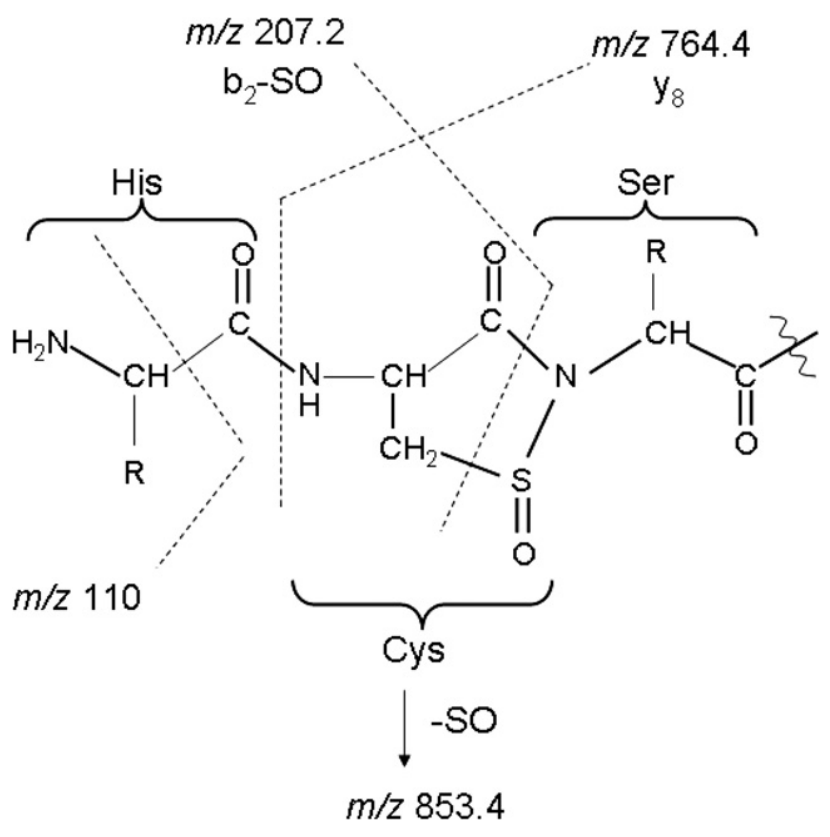

Scheme 1. Fragmentation pathways of doubly charged cysteine sulfinamide $\mathrm{HC}[\mathrm{S}(\mathrm{O}) \mathrm{N}] \mathrm{SAGIGRS}(+2)$ ions.

418.2 (indicated with asterisks) in Figure $3 \mathrm{~b}$ raised the possibility of the presence of isobaric impurities at the $\mathrm{m} / \mathrm{z} 451.2$ precursor ions as they were found to be present in Figure 4a, although at low abundance. Moreover, an intense peak at $m / z 451.2(+2)$ was most likely due to the loss of water in the ion trap MS/MS analysis of $\mathrm{HC}\left(\mathrm{SO}_{2} \mathrm{H}\right)$ SAGIGRS, as shown in Figure $4 \mathrm{~b}$. These observations led us to carefully investigate the purity as well as the mechanism of the formation of cysteine sulfinamide $m / z 451.2(+2)$ ions. To do this, we used an ion trap to perform $\mathrm{MS}^{2}$ and $\mathrm{MS}^{3}$ experiments on the $m / z 451.2(+2)$ parent ions formed in the oxidation reaction of HCSAGIGRS and on $451.2(+2)$ product ions formed by the water loss during the MS/MS analysis of $\left.\mathrm{HC}\left(\mathrm{SO}_{2} \mathrm{H}\right) \mathrm{SAGIGRS}\right)$. These spectra are shown in Figure 5. Differences can be seen between the MS/MS spectrum (Figure 5a) and the MS/MS/MS spectrum (Figure 5b). For example, the spectrum in Figure $5 b$ displayed a base peak at $m / z 418(+2)$ most likely due to a facile loss of water in MS/MS, followed by the neutral loss of $\mathrm{H}_{2} \mathrm{SO}_{2}$ in MS/MS/MS. Another ion at $\mathrm{m} / z 273\left(\mathrm{~b}_{2}\right.$ ion of $\left.\mathrm{HC}\left(\mathrm{SO}_{2} \mathrm{H}\right) \mathrm{SAGIGRS}\right)$, which is formed by the cleavage at the $\mathrm{C}$-terminal side of modified cysteine, is absent in Figure 5a. Likewise, the spectrum in Figure 5a contains a base peak at $m / z 442\left(-\mathrm{H}_{2} \mathrm{O}\right)$, a series of abundant $y$ ions and $a b_{6}$ ion that are of very low in intensity or absent in Figure $5 b$. The $y_{8}$ ion, which is more intense in Figure $5 \mathrm{a}$, is especially informative. This suggest that the $m / z 451.2(+2)$ ions formed by the loss of water from $\mathrm{HC}\left(\mathrm{SO}_{2} \mathrm{H}\right)$ SAGIGRS possess a different structure than the cysteine sulfinamide. Thus, based on the above experimental results, it seems most likely that the majority of the ions at $m / z 451.2(+2)$ belong to the cysteine sulfinamide product formed directly in the oxidation reaction. However, a minor contribution via the loss of water (most likely in-source) from $\mathrm{HC}\left(\mathrm{SO}_{2} \mathrm{H}\right) \mathrm{SAGIGRS}$ under our MS experimental conditions cannot be ruled out. In sum, we conclude that our data are consistent with multiple mechanisms for the formation of the cysteine sulfinamide product.

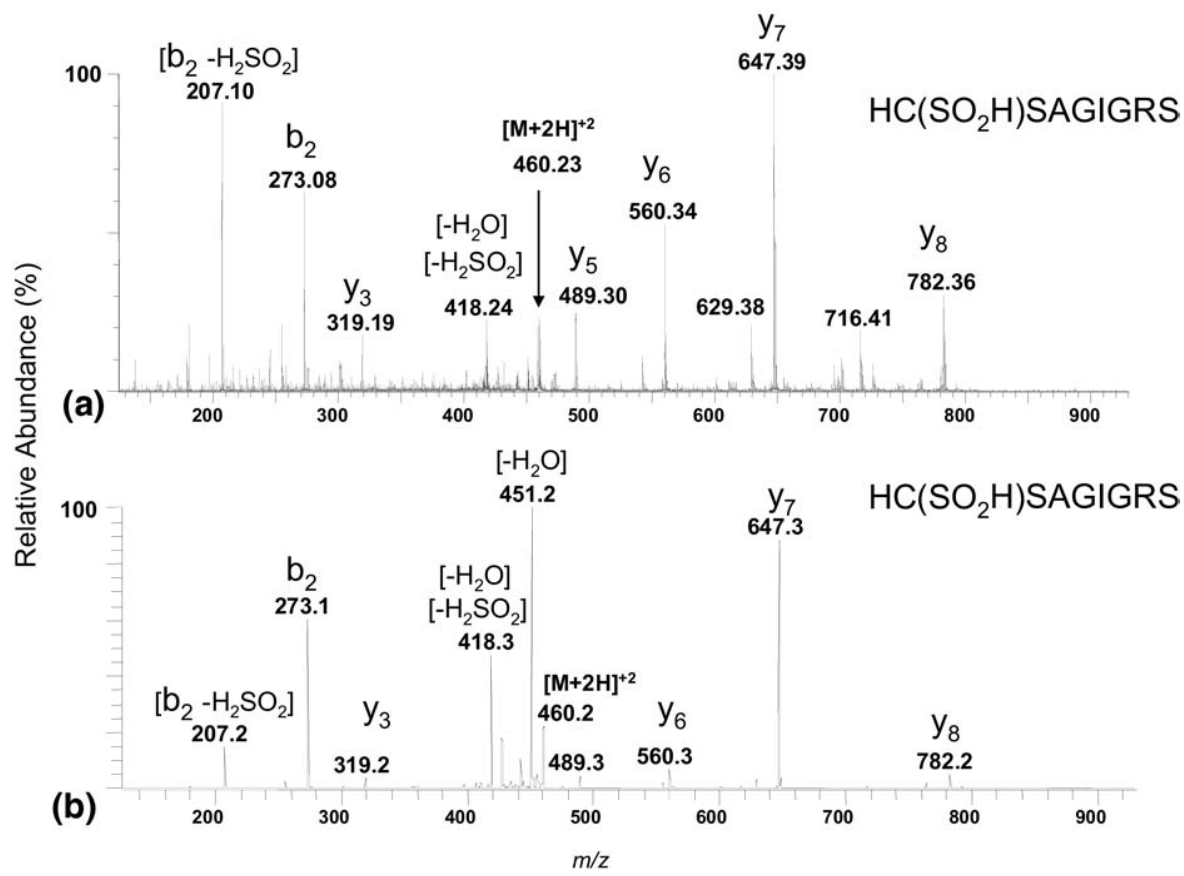

Figure 4. MS/MS spectra of doubly charged ions of $\mathrm{HC}\left(\mathrm{SO}_{2} \mathrm{H}\right)$ SAGIGRS $(\mathrm{m} / \mathrm{z} 460.2,+2)$ obtained by (a) Q-TOF and (b) ion trap instruments. 


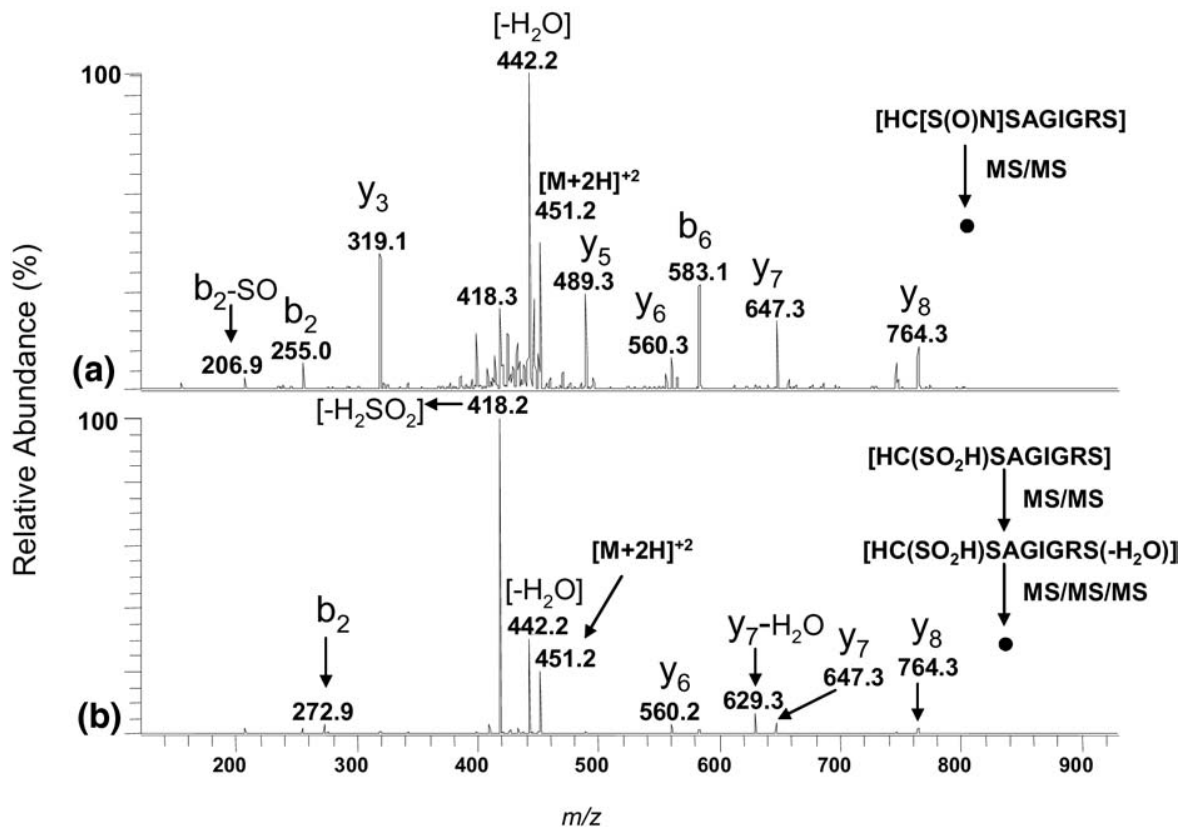

Figure 5. Ion trap spectra: (a) MS/MS spectrum of $\mathrm{m} / \mathrm{z} 451.2(+2)$ ions of $\mathrm{HC}[\mathrm{S}(\mathrm{O}) \mathrm{N}] \mathrm{SAGIGRS}$ and (b) MS/MS/MS spectrum of $\mathrm{m} / \mathrm{z} 451.2(+2)$ ions of $\left[\mathrm{HC}\left(\mathrm{SO}_{2} \mathrm{H}\right) \mathrm{SAGIGRS}\left(-\mathrm{H}_{2} \mathrm{O}\right)\right]$ produced in the MS/MS of $m / z 460.2(+2)$.

We have also carried out data-dependent nano LCMS/MS experiments to separate and characterize the cyclic cysteine sulfinamide oxidation product. We obtained the SICs for $m / z 451.2$ ions as well as $m / z 460.2$ ions (Figure 6) from an LC-MS/MS experiment. We found one MS/MS spectrum for a precursor ion of $\mathrm{m} / \mathrm{z}$ 451.2 (Figure 6d) at $14 \mathrm{~min}$ RT (Figure 6c) when the cysteine sulfinic acid oxidation product $(\mathrm{m} / \mathrm{z}$ 460.2) eluted (Figure $6 \mathrm{~b}$ ). We found another MS/MS spectrum for $m / z 451.2$ (Figure 6e) acquired at $31 \mathrm{~min}$ (Figure 6c). These two MS/MS spectra were recorded with similar $\mathrm{S} / \mathrm{N}$ ratios, but the spectra differ in several respects. The $\mathrm{y}_{8}$ ion at $m / z 764$ is completely absent from the MS/MS spectrum obtained at $14 \mathrm{~min}$ (Figure 6d), whereas it is clearly present in the MS/MS spectrum that is obtained at $31 \mathrm{~min}$ (Figure 6e). Also, the MS/MS spectrum at 31 min contains a more prominent series of y ions compared witih the MS/MS spectrum at 14 min. The formation of a low intensity $m / z 418$ ion in Figure 6e may be due to poor HPLC separation and contamination by the high concentration of the cysteine sulfinic acid oxidation product. These results suggest that the cysteine sulfinamide product (eluting predominantly at $31 \mathrm{~min}$ ) is formed directly from the oxidation of HCSAGIGRS peptide, and is not a water loss product of cysteine sulfinic acid (eluting predominantly at $14 \mathrm{~min}$ ).

These results are complementary to a recent study of PTP1B by Salmeen et al. who discovered a novel intermediate "cysteine sulfenamide" in the hydrogen peroxide mediated inactivation of PTP1B [15]. They proposed a mechanism for cysteine sulfenamide formation in which active site cysteine thiol undergoes oxidation to give sulfenic acid, followed by cyclization of the amide nitrogen onto the oxidized sulfur residue. These authors reinvestigated cysteine sulfenamide formation in PTP1B and found that the "sulfenamide bond" is stable for more than $5 \mathrm{~h}$ [34]. Nevertheless, in the current study, the cysteine sulfinamide structure that we characterized has an additional oxygen atom on the sulfur that could be formed when cysteine sulfenamide undergoes further oxidation. Salmeen et al. proposed an identical cysteine sulfinamide intermediate in the irreversible $\mathrm{H}_{2} \mathrm{O}_{2}$ oxidation of the cysteine thiol to cysteine sulfinic acid [35]. Based on these previously reported results and our current experimental findings, we propose a mechanism for the formation of a cysteine sulfinamide product starting with an $\mathrm{OH}^{-}$attack on the $-\mathrm{SH}$ group of cysteine in the HCSAGIGRS peptide as illustrated in Scheme 2.

To investigate the formation of cysteine sulfinamide via $\mathrm{H}_{2} \mathrm{O}_{2}$ oxidation of the HCSAGIGRS peptide, we incubated the peptide with $100 \mu \mathrm{M} \mathrm{H}_{2} \mathrm{O}_{2}$ at RT for 30 min while minimizing contamination by metal ions. We obtained a Q-TOF LC-MS/MS spectrum virtually identical to that of the cysteine sulfinamide ion at $m / z 451.2$ $(+2)$ formed in the oxidation reaction of HCSAGIGRS by Fenton reagent. These results suggest that cyclic cysteine sulfinamide may be a key intermediate in the irreversible oxidation by both $\mathrm{OH}^{-}$and $\mathrm{H}_{2} \mathrm{O}_{2}$ oxidants of the active site cysteine in PTP1B. 


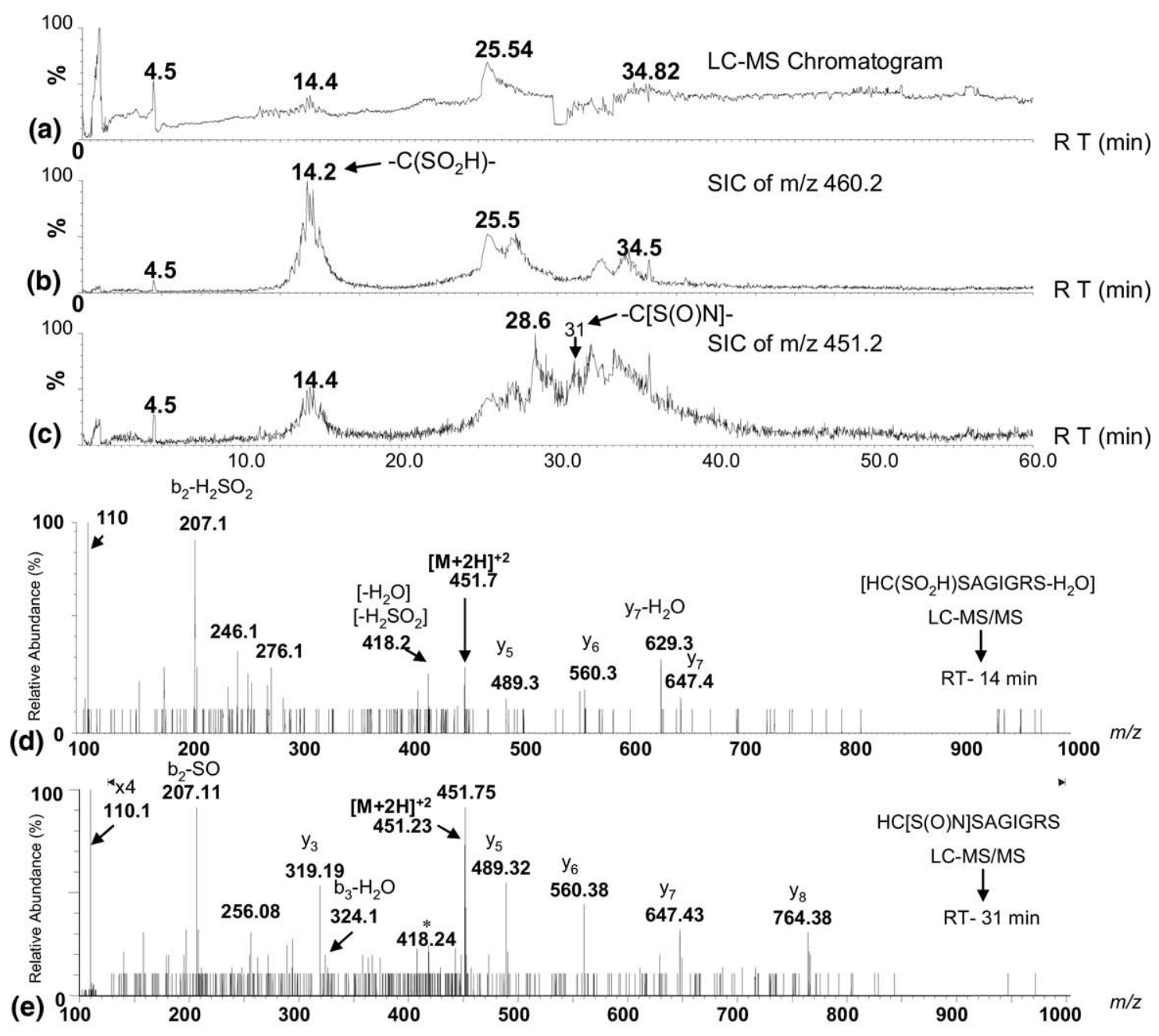

Figure 6. (a) LC-MS chromatogram of products formed in the oxidation reaction of HCSAGIGRS peptide with Fenton reagent and selected ion chromatograms (SIC) of (b) 460.2 ions and (c) 451.2 ions. LC-MS/MS spectra of $\mathrm{m} / \mathrm{z} 451.2(+2)$ ions acquired at RTs (d) at $14 \mathrm{~min}$ and (e) at $31 \mathrm{~min}$.

\section{Characterization of Cysteine Sulfenic Acid [HC(SOH)SAGIGRS]}

To investigate the formation of a potential cysteine sulfenic acid intermediate, the Fenton reagent oxidation reaction mixture was infused directly into a Q-TOF Micro mass spectrometer immediately after addition of the reagent to HCSAGIGRS peptide. A clear peak at $m / z$ 903.4 can be seen in the mass spectrum (Figure 1a). The MS/MS spectrum of this $\mathrm{m} / \mathrm{z} 903.4$ ion (Figure 1b) shows a series of $y$ ions, including $\mathrm{y}_{3}$ and $\mathrm{y}_{5}-\mathrm{y}_{7}$, which confirmed the amino acid sequence SAGIGRS. Histidine modification is unlikely because of the formation of its abundant immonium ion at $\mathrm{m} / \mathrm{z} 110$. These data indirectly suggest that cysteine is modified. In addition, the ion at $m / z 853.4$ indicating the loss of neutral $\mathrm{H}_{2} \mathrm{SO}$ from the parent ion confirmed that cysteine is modified to cysteine sulfenic acid [HC(SOH)SAGIGRS]. A low abundance ion at $\mathrm{m} / \mathrm{z} 853$ ion formed by the loss of neutral $\mathrm{H}_{2} \mathrm{~S}$ is also present in Figure 2a. A similar $\mathrm{H}_{2} \mathrm{SO}$ loss was observed in the MS/MS spectrum of another peptide, PRC(SOH)GVPDVA ( $m / z$ 929.4), which we recently characterized as a stable sulfenic acid oxidation product [38]. Furthermore, modification of cysteine to cysteine sulfenic acid induced the preferred formation of abundant $y$ ions over $b$ ions as in the MS/MS spectra of cysteine sulfinic acid [ $\mathrm{HC}\left(\mathrm{SO}_{2} \mathrm{H}\right) \mathrm{SAGIGRS}$ ] and cysteine sulfonic acid [ $\mathrm{HC}\left(\mathrm{SO}_{3} \mathrm{H}\right) \mathrm{SAGIGRS}$ (Figure 1c and d). Figure $1 b-d$ show that the $y_{7}$ ion formed by the facile cleavage at C-terminal side of the modified cysteine residue is relatively intense while it is almost absent in the MS/MS spectrum of unmodified HCSAGIGRS (Figure 2a). Thus, cysteine sulfenic acid undergoes very similar fragmentation as cysteine sulfinic acid and cysteine sulfonic acid in our MS/MS experiments. It has been proposed that cysteine sulfenic acids in proteins are stabilized by hydrogen bonding with amino or carbonyl groups [38, 40]. We suggest similar hydrogen bonding interactions to stabilize cysteine sulfenic acid in the PTB1B active site sequence $\mathrm{HC}(\mathrm{SOH}) \mathrm{SAGIGRS}$, perhaps due to strong hydrogen bonding between the $\mathrm{SOH}$ group and the imida- 


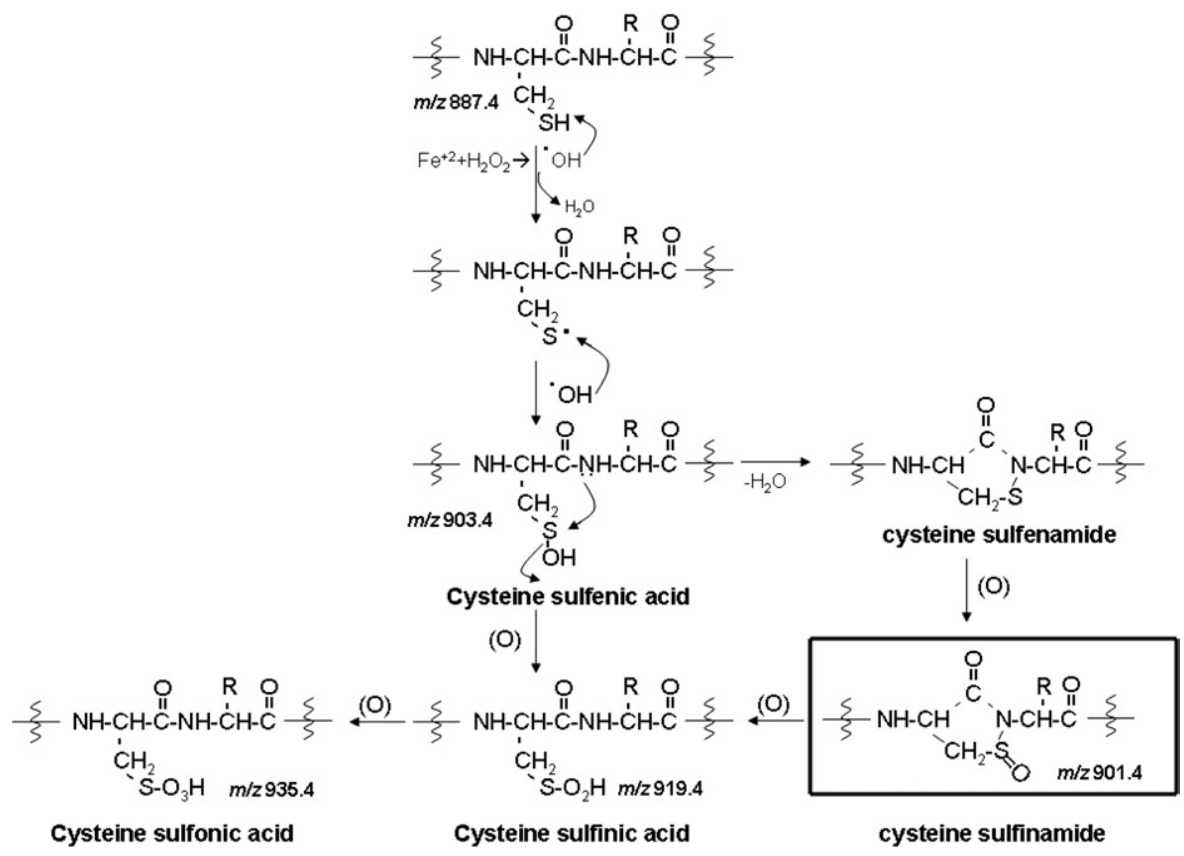

Scheme 2. Proposed mechanism for the formation of cysteine sulfinamide HC[S(O)N]SAGIGRS product and its oxidation to cysteine sulfonic acid.

zole ring of histidine. These results are consistent with evidence for the presence of cysteine sulfenic acid in PTP1B in response to $\mathrm{H}_{2} \mathrm{O}_{2}$ oxidation obtained by Barrett et al. [41] and Denu et al. [42], using the trapping reagent $\mathrm{NBD}-\mathrm{Cl}$. While there are many reports describing the significance of cysteine sulfenic acid intermediates in redox signaling in biologically important proteins (reviewed in [43], our results do not directly demonstrate that cysteine sulfenic acid is an intermediate for the formation of cysteine sulfinamide in PTP1B.

\section{Conclusions}

We used mass spectrometry to characterize several oxidation products of a synthetic peptide containing the PTP1B active site sequence motif, HCSAGIGRS. We found a previously unknown oxidation product, cysteine sulfinamide, which may be formed in the irreversible oxidation of catalytic cysteine in PTP1B. The direct identification of cysteine sulfenic acid in our experiments suggests that it might be a key intermediate in the formation of the cysteine sulfinamide product. Our findings suggest plausible $\mathrm{OH}$ and $\mathrm{H}_{2} \mathrm{O}_{2}$ mediated oxidation products of PTP1B that may be formed when the Fe-catalyzed Fenton reaction prevails in cellular responses to high oxidative stress situations, increase in $\mathrm{H}_{2} \mathrm{O}_{2}$ levels, and/or exposure to high-energy irradiation such as $\mathrm{x}$-rays, $\gamma$ rays, or UV radiation.

\section{Acknowledgments}

The authors gratefully acknowledge support from $\mathrm{NIH}$ grants $\mathrm{P} 30$ CA016087 and 1 S10 RR017990 to T.A.N

\section{References}

1. Alonso, A.; Sasin, J.; Bottini, N.; Friedberg, I.; Osterman, A.; Godzik, A.; Hunter, T.; Dixon, J.; Mustelin, T. Protein tyrosine phosphatases in the human genome. Cell 2004, 117, 699-711.

2. Andersen, J. N.; Jansen, P. G.; Echwald, S. M.; Mortensen, O. H. Fukada, T.; Del Vecchio, R.; Tonks, N. K.; Moller, N. P. A genomic perspective on protein tyrosine phosphatases: Gene structure, pseudogenes, and genetic disease linkage. FASEB J. 2004, 18, 8-30.

3. Barford, D.; Das, A. K.; Egloff, M. P. The structure and mechanism of protein phosphatases: Insights into catalysis and regulation. Annu. Rev. Biophys. Biomol. Struct. 1998, 27, 133-164.

4. Jackson, M. D.; Denu, J. M. Molecular reactions of protein phosphatasesinsights from structure and chemistry. Chem. Rev. 2001, 101, 2313-2340.

5. Jia, Z.; Barford, D.; Flint, A. J.; Tonks, N. K. Structural basis for phosphotyrosine peptide recognition by protein tyrosine phosphatase 1B. Science 1995, 268, 1754-1758.

6. Zhang, Z. Y. Protein tyrosine phosphatases: Structure and function substrate specificity, and inhibitor development. Annu. Rev. Pharmacol. Toxicol. 2002, 42, 209-234.

7. Lou, Y. W.; Chen, Y. Y.; Hsu, S. F.; Chen, R. K.; Lee, C. L.; Khoo, K. H.; Tonks, N. K.; Meng, T. C. Redox regulation of the protein tyrosine phosphatase PTP1B in cancer cells. J. FEBS 2008, 275, 69-88.

8. Denu, J. M.; Dixon, J. E. Protein tyrosine phosphatases: Mechanisms of catalysis and regulation. Curr. Opin. Chem. Biol. 1998, 2, 633-641.

9. Salmeen, A.; Barford, D. Functions and mechanisms of redox regulation of cysteine-based phosphatases. Redox Signaling 2005, 7, 560-577.

10. Lee, S. R.; Kwon, K. S.; Kim, S.R.; Rhee, S. G. Reversible inactivation of protein-tyrosine phosphatase $1 \mathrm{~B}$ in A431 cells stimulated with epidermal growth factor. J. Biol. Chem. 1998, 273, 15366-15372.

11. Barrett, W. C.; DeGnore, J. P.; Konig, S.; Fales, H. M.; Keng, Y. F.; Zhang Z. Y.; Yim, M. B.; Chock, P. B. Regulation of PTP1B via glutathionylation of the active site cysteine 215. Biochemistry 1999, 38, 6699-6705.

12. Elchebly, M.; Payette, P.; Michaliszyn, E.; Cromlish, W.; Collins, S.; Loy, A. L.; Normandin, D.; Cheng, A.; Himms-Hagen, J.; Chan, C. C.; Ramachandran, C.; Gresser, M. J.; Tremblay, M. L.; Kennedy, B. P. Increased insulin sensitivity and obesity resistance in mice lacking the protein tyrosine phosphatase-1B gene. Science 1999, 283, 1544-1548

13. Klaman, L. D.; Boss, O.; Peroni, O. D.; Kim, J. K.; Martino, J. L. Zabolotny, J. M.; Moghal. N.; Lubkin, M.; Kim, Y. B.; Sharpe, A. H.; Stricker-Krongrad, A.; Shulman, G. I.; Neel, B. G.; Kahn, B. B. Increased energy expenditure, decreased adiposity, and tissue-specific insulin sensitivity in protein-tyrosine phosphatase 1B-deficient mice. Mol. Cell Biol. 2000, 20, 5479-5489.

14. Goldstein, B. J. Protein-tyrosine phosphatase 1B (PTP1B): A novel therapeutic target for type 2 diabetes mellitus, obesity, and related states of insulin resistance. Curr. Drug Targets Immune Endocr. Metabol. Disord. 2001, 1, 265-275.

15. Salmeen, A.; Andersen, J. N.; Myers, M. P.; Meng, T. C.; Hinks, J. A Tonks, N. K.; Barford, D. Redox regulation of protein tyrosine phos- 
phatase 1B involves a sulphenyl-amide intermediate. Nature 2003, 423, 769-773.

16. Stadtman, E. R. Protein oxidation and aging. Science 1992, 257, 1220 1224.

17. Stadtman, E. R.; Berlett, B. S. Reactive oxygen-mediated protein oxidation in aging and disease. Drug Metab. Rev. 1998, 30, 225-243.

18. Rhee, S. G. Redox signaling: Hydrogen peroxide as intracellular messenger. Exp. Mol. Med. 1999, 31, 53-59.

19. Fenton H. J. H. The oxidation of tartaric acid in the presence of iron. Proc. Chem. Soc. 1893, 9I, 113.

20. Koppenol, W. H.; Moreno, J. J.; Pryor, W. A.; Ischiropoulos, H. Beckman, J. S. Peroxynitrite: A cloaked oxidant from superoxide and nitric oxide. Chem. Res. Toxicol. 1992, 5, 834-842.

21. Hodges, G. R.; Ingold, K. U. Cage escape of geminate radical pairs can produce peroxynitrate from peroxynitrite under a wide variety of experimental conditions. J. Am. Chem. Soc. 1999, 121, 10695-10701.

22. Marnett, L. J.; Riggins, J. N.; West, J. D. Endogenous generation of reactive oxidants and electrophiles and their reactions with DNA and protein. J. Clin. Invest. 2003, 111, 583-593.

23. Stadtman, E. R.; Berlett, B. S. Fenton Chemistry, Amino Acid Oxidation. J. Biol. Chem. 1991, 266, 17201-17211.

24. Hugginsh, T. G.; Wells-Knecht, M. C.; Detorie, N. A.; Baynes, J. W.; Thorpe, S. R. Formation of o-tyrosine and dityrosine in proteins during radiolytic and metal catalyzed oxidation. J. Biol. Chem. 1993, 268, 12341-12347.

25. Neuzil, J.; Gebicki, J. M.; Stocker, R. Radical-induced chain oxidation of proteins and its inhibition by chain-breaking antioxidants. Biochem. J. 1993, 293, 601-606.

26. Stadtman, E. R.; Berlett, B. S. Protein Oxidation in Aging, Disease, and Oxidative Stress. J. Biol. Chem. 1997, 272, 20313-20316.

27. Levin, R. L.; Stadtman, E. R. Oxidative modifications of proteins during aging. Exp. Gerontol. 2001, 36, 1495-1502.

28. Stadtman, E. R.; Levin, R. L. Free radical-mediated oxidation of free amino acids and amino acid residues in proteins. Amino Acids 2003, 25, 207-218.

29. Stadtman, E. R.; Levin, R. L. Protein oxidation. Ann. N.Y. Acad. Sci. U.S.A. 2000, 899, 191-208.

30. Stadtman, E. R. Role of oxidant species in aging. Curr. Med. Chem. 2004, $11,1105-1112$

31. Dalle-Donne, I.; Scaloni, A.; Giustarini, D.; Cavarra, E.; Tell, G.; Lungarella, G.; Colombo, R.; Rossi, R.; Milzani, A. Proteins as biomarkers of oxidative/nitrosative stress in diseases: The contribution of redox proteomics. Mass Spectrom. Rev. 2005, 24, 55-99.
32. Marnett, L. J.; Riggins, J. N.; West, J. D. Endogenous generation of reactive oxidants and electrophiles and their reactions with DNA and protein. J. Clin. Invest. 2003, 111, 583-593.

33. Stadtman, E. R. Protein oxidation in aging and age-related Diseases Ann. N.Y. Acad. Sci. U.S.A. 2001, 928, 22-38.

34. Caselli, A.; Marzocchini, R.; Camiri, G.; Manao, G.; Moneti, G.; Pieraccini, G.; Ramponi, G. The inactivation mechanism of low molecular weight phosphotyrosine-protein phosphatase by $\mathrm{H}_{2} \mathrm{O}_{2}$. J. Biol. Chem. 1998, 273, 32554-32560.

35. Salmeen, A.; Barford, D. Functions and mechanisms of redox regulation of cysteine-based phosphatases. Redox Signaling 2005, 7, 560-577.

36. Wang, Y.; Vivekananda, S.; Men, L.; Zhang, Q. Fragmentation of Protonated Ions of Peptides Containing Cysteine, Cysteine Sulfinic Acid, and Cysteine Sulfonic Acid. J. Am. Soc. Mass Spectrom. 2004, 15 697-702.

37. Fu, X.; Mueller, D. M.; Heinecke, J. W. Generation of intramolecular and intermolecular sulfenamides, sulfinamides, and sulfonamides by hypochlorous acid: A potential pathway for oxidative cross-linking of low-density lipoprotein by myeloperoxidase. Biochemistry 2002, 41, 1293-1301.

38. Shetty, V.; Spellman, D. S.; Neubert, T. A. Characterization by tandem mass spectrometry of stable cysteine sulfenic acid in a cysteine switch peptide of matrix metalloproteinases. J. Am. Soc. Mass Spectrom. 2007, $18,1544-51$.

39. Sivaramakrishnan, S.; Keerthi, K.; Gates, K. S. A chemical model for redox regulation of protein tyrosine phosphatase $1 \mathrm{~B}$ (PTP1B) activity. J. Am. Chem. Soc. 2005, 127, 10830-10831.

40. Claiborne, A.; Yeh, Y. I.; Mallett, T. C.; Luba, J.; Crane, E. J.; Charrier, V. Parsonage, D. Protein-sulfenic acids: Diverse roles for an unlikely player in enzyme catalysis and redox regulation. Biochemistry 1999, 28, 15407-15416.

41. Barrett, W. C.; DeGnore, J. P.; Keng, Y. F. Zhang, Z. Y.; Yim, M. B. Chock, P. B. Roles of superoxide radical anion in signal transduction mediated by reversible regulation of protein tyrosine phosphatase $1 \mathrm{~B}$. J. Biol. Chem. 1999, 274, 34543-34546.

42. Denu, J. M.; Tanner, K. G. Specific and reversible inactivation of protein tyrosine phosphatases by hydrogen peroxide: Evidence for a sulfenic acid intermediate and implications for redox regulation. Biochemistry 1998, 37, 5633-5642.

43. Poole, L. B.; Karplus, P. A.; Clairborne, A. Protein sulfenic acids in redox signaling. Annu. Rev. Pharmacol. Toxicol. 2004, 44, 325-47. 